\title{
Anti-Collision and Anti-Mired Wheelchair Prototype
}

\author{
Indranata Utama Panggalo ${ }^{1}$, Christa Elena Blandina Bire ${ }^{1}$, Ade Manu Gah ${ }^{1}$ \\ \{indrapanggalo@gmail.com, christa.eren@gmail.com, adekpg@gmail.com\} \\ Jurusan Teknik Elektro, Politeknik Negeri Kupang ${ }^{1}$
}

\begin{abstract}
DC Motorized wheelchairs have been developed in past few years to facilitate its users with convenience and ease. However, only few researches focusing on wheelchairs automatic breaking system through speed reduction. Some of users have slow response in controlling the motorized wheelchair hence possibility to collide or to fall down is high. This research is focusing on the implementation of speed reduction method in DC motorized wheelchair to prevent collisions and also to protect the wheelchair and user from falling down. The system implanted on the control system will automatically reduce or stop the motion of the wheelchair when it detects turns or a sharp drop such as stairway. The implanted system used ultrasonic sensors to detect the presence of a barrier or a sharp drop. Eight sensors are implanted on the front and rear side of a wheelchair. When the sensors detect a presence of a barrier in 1 meter distance, speed will be reduced to $50 \%$ and when the distance is $30 \mathrm{~cm}$, velocity will drop to zero. To prevent from falling down, the speed will be reduced to zero when it detects a drop more than $2 \mathrm{~cm}$ deep. The system has been tested and it works properly as required.
\end{abstract}

Keywords: Wheelchair, Microcontroller, ultrasonic censor, Anti-Collision, Anti-mired down

\section{Introduction}

A wheelchair is an instrument developed to help people who have difficulties, either due to illness, injury, old age or disability, to mobile. Majority of wheelchairs on the market today are still operated manually. They must be pushed by its users and or by the helpers in order to move. The manual operation wheelchairs are considered inefficient because it requires extra energy to move or to control it.

Based on research conducted in 2009 in several hospitals and homes of disable people, it was found that the appreciation of people with disabilities for the need for automatic wheelchair is pretty high. This happened because they were less satisfied with the performance of manual wheelchair due to its incomplete system (58.3\%), inconvenience $(25 \%)$ and difficult operation $(4.1 \%)$. The respondent also stated that current manual wheelchairs are still not able to help them to carry out most of their activities (12.6\%) [1].

In order to provide convenience and ease, in regard to the various physical of the users, motorized wheelchairs are largely manufactured in these past few years [2]. Most of the electric wheelchairs in the market are driven by DC motor and equipped with several types of control systems. Control systems on the wheelchair marketed today can be joysticks, mobile phones, voice commands,or electromyography. Based on studies, majority of wheelchairs controls are made with emphasis on how the wheelchair maneuvered according to instructions but only few researches really focusing on the security system of the wheelchairs such as on 
its breaking system. Some wheelchair users, especially elderly people who experience a decrease in reflex system, are at risk of collision or fall due to slow response in controlling wheelchair.

Based on the problems described above, the research conducted is focused on the wheelchair security system, where the speed reduction method will be implemented into an automatic security system. In this research, an electric wheelchair prototype equipped with manual and automatic control system will be built. The automatic security system will automatically reduce or stop the movement of a wheelchair if the system detects a barrier or a sharp drop at a specified distance either at front or at rear side.

\section{Methodology}

There are 3 main activities carried out in this research:

1. Observation

Observations are made on various brands and types of electric wheelchairs in the market by focusing on its price, control system, and safety. The result shows that in terms of cost, motorized wheelchair is quite expensive. It can reach tens of millions rupiah in the market. It is also found that majority of these electric wheelchairs are controlled via joysticks that serves to brake and move the wheelchair forward/ backward. Most of these electric wheelchairs have not equipped with automatic braking system to prevent collision or fall especially when its user is careless in controlling the wheelchair.

2. Literature Studies

Literature studies are focused on previous researches related to the improvement of electric wheelchair's control system. The information obtained from this activity will be used as a reference to form alternative solutions that will be implemented in the wheelchair system built.

3. Experiment

The experimental method can be regarded as a research method used to look for the effect of certain treatments on others under controlled conditions [3]. In this activity, solutions made based on observations and literature studies will be implemented on the prototype wheelchair. Various tests will be carried out to improve the performance of the electric wheelchair.

\section{System Design}

The prototype wheelchair developed in this study can be described as follows:

- Wheelchair drive uses 2 DC motors connected to the wheels using belt. Wheelchairs can move forward, backward, turn left and turn right.

- The wheelchair is controlled through a joystick. The control system will be equipped with an automatic safety system for speed reduction and sudden braking. The automatic safety system consists of eight ultrasonic sensors that connected to microcontroller and DC motors.

- $\quad$ Reduction of motor speed starts when the sensor detects a barrier at a certain distance. The microcontroller will automatically stop the wheelchair when it is moving closer to the 
barrier to prevent collision. This operation is applied on both direction of the wheelchair (forward and backward)

- If the sensors detect downward stairway or steepness over a certain level, the system will automatically brake the wheelchair to avoid accidents such as mired or overturned.

The design of the prototype will cover hardware design and software design.

1. Hardware Design

Hardware design will be carried out on the wheelchair body and on components of the control system.

a. Modification on the body of the wheelchair.

In order to move the wheelchair electrically, a DC motor and a battery as power supply are installed in a manual wheelchair. A Gear system will also be assembled on the left and right wheels and this system will be connected to DC motor through a belt.

b. Control System

Control Systems Hardware consists of several components as follows:

- An Arduino Mega as Processor

- Eight Ultrasonic sensors to detect the presence of a barrier or a drop.

- A joystick for manual control of the wheelchair

- Two Motor drivers to control the speed rotation and its direction. Each motor drive is installed for each direction (forward and backward).

- A 12 Volt battery as supply

- A Voltage regulator

The picture below shows the design of the control system built in the wheelchair

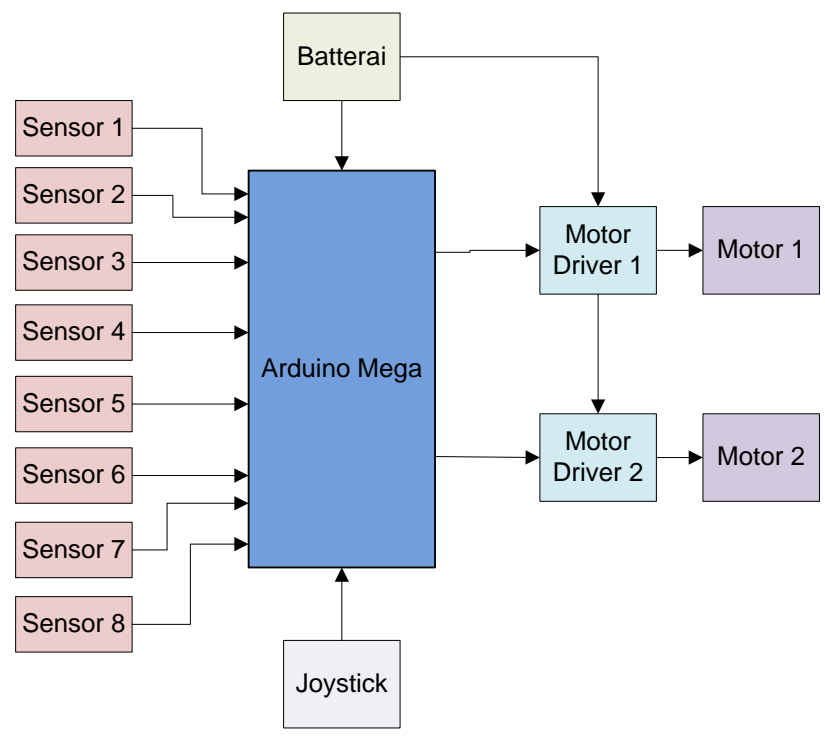

Fig.1. Block Diagram of Motor Controller 


\section{Software design}

There are two types of control system built on the wheelchair; manual control that carried through the joystic and automatic control system that coordinates with the sensors. Software component of the wheelchair works as a part of the control system. It manages the work of the system by processing the signals received either from the joystick or from the sensors. The command of the wheelchairs is programmed using $\mathrm{C}$ language.

The Algorithm of manual control of the system carried through joystick is shown on diagram below

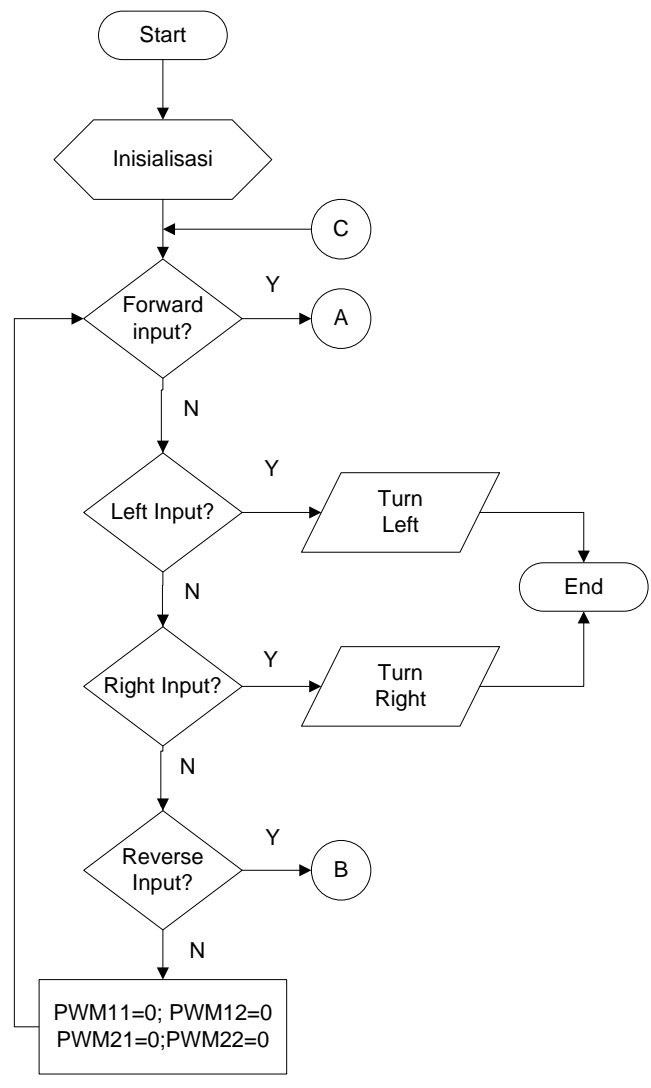

Fig. 2. Manual Control of the Wheelchair

The components of automatic control systems consist of 8 ultrasonic sensors connected to a microcontroller and 2 motor drives. Four of ultrasonic sensors (sensor 1 to 4 ) are installed on the front side of the wheelchair for automatic control in forward direction while the other sensors (sensor 5 to 8) are assembled on the rear side for backward control. Sensor 1,2,5 and 6 work to detects the presence of the barrier in a certain distance while the sensor 3,4,7,8 detects the presence of sharp drop/ steepness on a certain level. When the sensors detect a presence of a barrier or a sharp drop, the signal will be sent and processed in microprocessor. Later, the Microprocessor will send command signal to motor drives either to reduce the speed or to stop 
the motor. The algorithm of the automatic control for forward and backward direction is shown in the diagrams below:

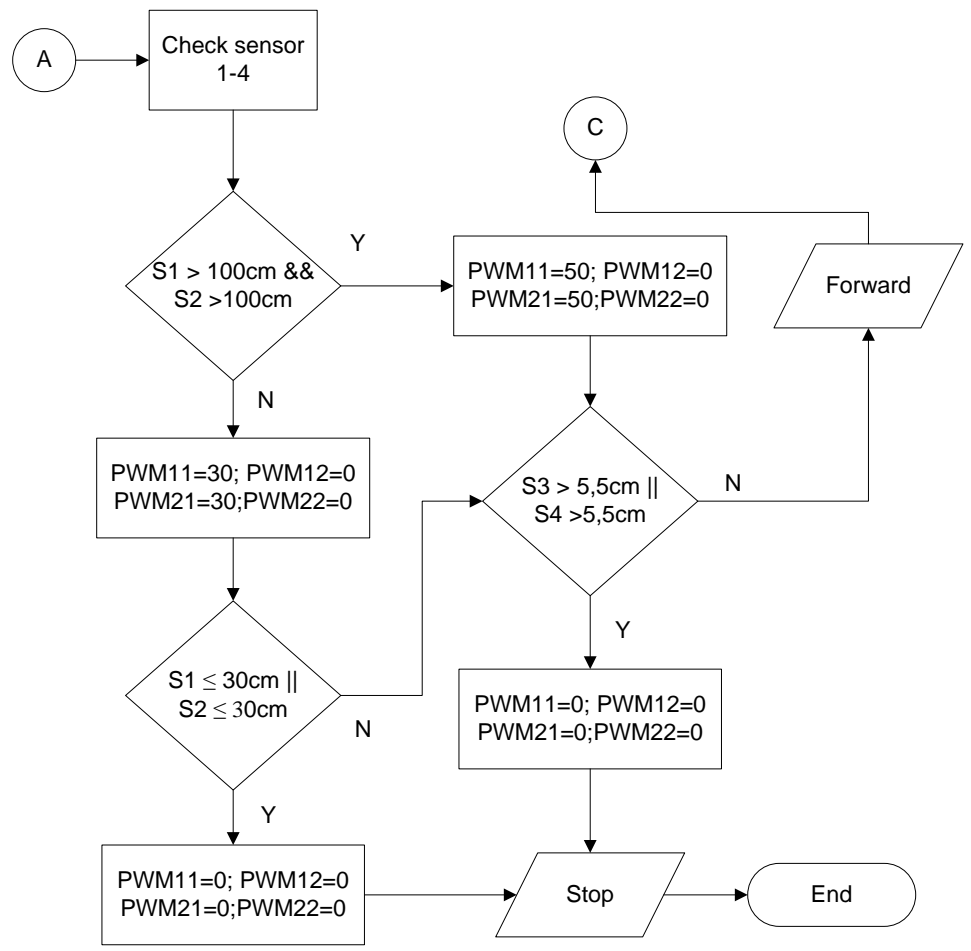

Fig.3. Automatic Control for Forward direction 


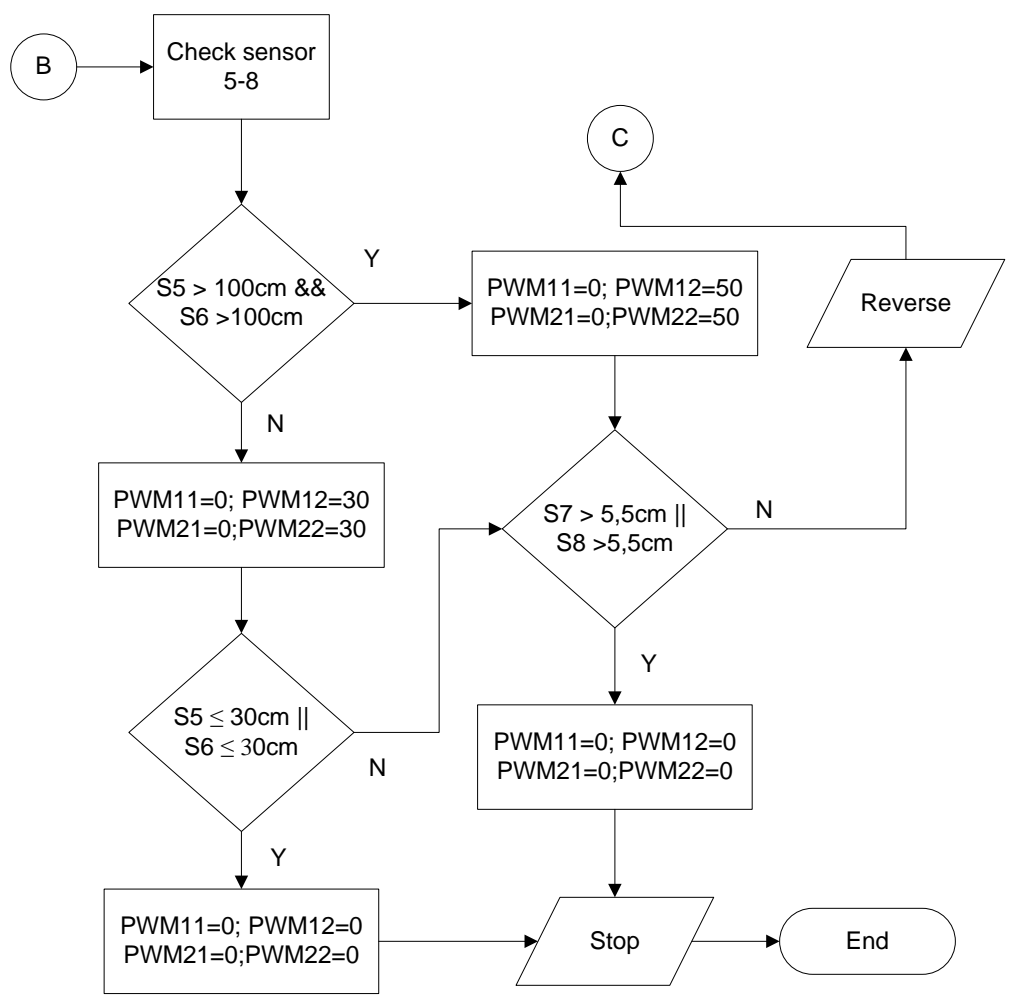

Fig.4. Automatic control for backward direction

\section{Results}

The speed of the the motorized wheelchair is set to $2 \mathrm{~m} / \mathrm{s}$ or $7.2 \mathrm{~km} / \mathrm{hr}$ by considering the user safety and need and this wheelchair has 2 types of Control system; manual and automatic control system. Manual system is carried through the joystick while the automatic one is done through coordination of several electronic components such as sensors and microprocessor.

After applying some tests to the wheelchair, the manual control carried through joystick worked successfully as commanded. The wheelchair is able to move in four directions (forward, backward, left and right) and also able to brake manually as intended. The automatic control is also works perfectly as the motor's speed reduced to certain level or stopped when certain conditions met.

As described on the previous section, the attributes of the automatic control system consist of 8 ultrasonic sensors connected to a processor and 2 motor drives. The ultrasonic sensors (sensor 1 to 4 ) are installed on the front side of the wheelchair for automatic control in forward direction while the other sensors (sensor 5 to 8 ) are on the rear side for backward control. Sensor 1,2,5 and 6 work to detects the presence of the barrier in a certain distance while the sensor 3,4,7,8 detects the presence of sharp drop/ steepness on a certain level. When the sensors detect a presence of a barrier or a sharp drop, the signal will be sent and processed in microprocessor. Later, the Microprocessor will send command signal to motor drives either to reduce the speed or to stop the motor by. When the sensors detect a presence of a barrier in $1 \mathrm{~m}$ distance, the speed is reduced to $1 \mathrm{~m} / \mathrm{s}$ and when the distance is less than $30 \mathrm{~cm}$, the speed 
is dropped to zero and the motion is stopped. When the sensor detects a sharp drop (more than $2 \mathrm{~cm}$ deep), the system applied a sudden brake to avoid fall.

The picture below shows the prototype of the wheelchair
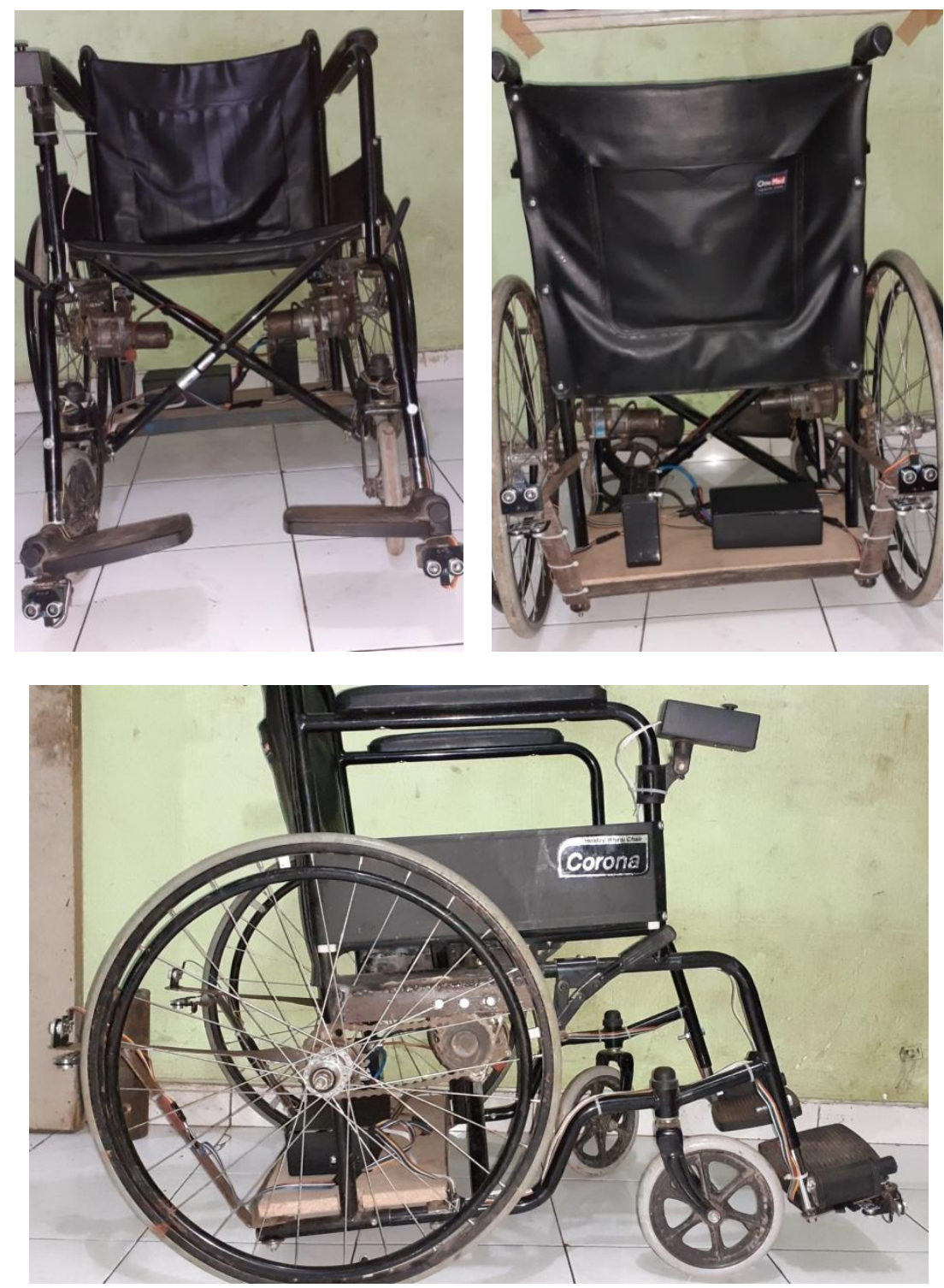

Fig.5. The prototype of the wheelchair

The ultrasonic type used in this research is HC-SR04. This sensor has minimum measuring limit up to $2 \mathrm{~cm}$ and able to measure a distance up to $50 \mathrm{~cm}$ [4]. The characteristics 
of this sensor is deemed accurate to be applied in this research. The speed reduction is done through the implementation of PWM method programmed in Arduino. The smaller the PWM value set, the rotation will be slower. For $2 \mathrm{~m} / \mathrm{s}$ speed, the value of PWM set in arduino is 120 .

Table 1. Performance of the controlled wheelchair built in this research

\begin{tabular}{|c|c|c|c|c|c|c|c|c|c|c|c|c|}
\hline & \multirow{2}{*}{ Distance } & \multicolumn{4}{|c|}{ Forward Sensor } & \multicolumn{4}{|c|}{ Bacward Sensor } & \multicolumn{3}{|c|}{ Velocity } \\
\hline & & $1^{\mathrm{st}}$ & $2^{\text {nd }}$ & $3^{\text {th }}$ & $4^{\text {th }}$ & $5^{\text {th }}$ & $6^{\text {th }}$ & $7^{\text {th }}$ & $8^{\text {th }}$ & $2 \mathrm{~m} / \mathrm{s}$ & $1 \mathrm{~m} / \mathrm{s}$ & Stop \\
\hline \multirow[t]{10}{*}{ Obstacle } & $>100 \mathrm{~cm}$ & $\sqrt{ }$ & $\sqrt{ }$ & - & - & - & - & - & - & $\sqrt{ }$ & - & - \\
\hline & & - & - & - & - & $\sqrt{ }$ & $\sqrt{ }$ & - & - & $\sqrt{ }$ & - & - \\
\hline & $<100 \mathrm{~cm}$ & $\sqrt{ }$ & - & - & - & - & - & - & - & - & $\sqrt{ }$ & - \\
\hline & & - & $\sqrt{ }$ & - & - & - & - & - & - & - & $\sqrt{ }$ & - \\
\hline & & - & - & - & - & $\sqrt{ }$ & - & - & - & - & $\sqrt{ }$ & - \\
\hline & & - & - & - & - & - & $\sqrt{ }$ & - & - & - & $\sqrt{ }$ & - \\
\hline & $<30 \mathrm{~cm}$ & $\sqrt{ }$ & - & - & - & - & - & - & - & - & - & $\sqrt{ }$ \\
\hline & & - & $\sqrt{ }$ & - & - & - & - & - & - & - & - & $\sqrt{ }$ \\
\hline & & - & - & - & - & - & - & $\sqrt{ }$ & - & - & - & $\sqrt{ }$ \\
\hline & & - & - & - & - & - & - & - & $\sqrt{ }$ & - & - & $\sqrt{ }$ \\
\hline \multirow[t]{4}{*}{ Drop } & $>2 \mathrm{~cm}$ & - & - & $\sqrt{ }$ & - & - & - & - & - & - & - & $\sqrt{ }$ \\
\hline & & - & - & - & $\sqrt{ }$ & - & - & - & - & - & - & $\sqrt{ }$ \\
\hline & & - & - & - & - & - & - & $\sqrt{ }$ & - & - & - & $\sqrt{ }$ \\
\hline & & - & - & - & - & - & - & - & $\sqrt{ }$ & - & - & $\sqrt{ }$ \\
\hline
\end{tabular}

\section{Conclusion}

The DC motorized electric wheelchair system built in the research has manual control systems and automatic control systems. The manual control system is carried out through a joystick and the automatic control system is carried out through coordination of electronic components such ultrasonic sensors, drivers and a programmed microprocessor.

From the experiment, When the sensors detect a presence of a barrier in $1 \mathrm{~m}$ distance, the speed of the wheelchair is reduced to $1 \mathrm{~m} / \mathrm{s}$ and when the distance is less than $30 \mathrm{~cm}$, the speed is dropped to zero and the motion is stopped. When the sensors detect a sharp drop (more than $2 \mathrm{~cm}$ deep), the system applied a sudden brake to avoid fall. To solve the issue of a presence of remaining torque when the speed is reduced to zero, a reverse motion method is added in the command program and carried through driver BTS 7960

\section{Acknowledgement}

Through this journal, we would like to say thank you to all those who have helped the success of this project.

1. Kemeristekdikti for giving an oppotunity to take a part in the PDP scheme 2018. Thank you also for financial support during the work of the project

2. Unit of P3M Politeknik Negeri Kupang for your assistance. 


\section{References}

[1]Pradana, Angga, Ferry Hidayat, Muhammad Agus Taksiono, Muhammad Faisal Winarto, : Rancang Bangun Electricwheelchair Controlled By Android Device With Speech Recognition Commands Function, Institut Teknologi Sepuluh Nopember (2014)

[2] Yunanto , Daniel Christian, Handry Khoswanto, Petrus Santoso : Sistem Kendali dan Pemantauan Kursi Roda Elektrik, Vol. 9, No. 2, Jurnal Teknik Elektro Universitas Petra (2016)

[3]Sugiyono : Metode Penelitian Pendidikan Pendekatan Kuantitatif, kualitatif dan R\&D. Bandung: Alfabeta (2009)

[4]Indrayana, I Putu Tedy, Trisna Julian, Kuwat Triyana : Testing Data Acquisition of Ultrasonic Sensor HC-SR04 using Atmega 8535 Microcontroller, Volume 40 Volume 6, Nomor 1, , JURNAL UNIERA (2017) 